\title{
A Selection Model for In-Terminal Container Handling Systems
}

Wen-Chih Huang

Associate Professor, Department of River and Harbor Engineering, National Taiwan Ocean Juniversity, P.O. Box 7-107, Keelung, Taiwan 20224, R.O.C.

Chin-Yuan Chu

Section Chief, Ministry of Transportation and Communication, Institute of Transportation, Research Center of Harbor and Marine Technology, No. 2, Chung-Hen 10th Rd., Wuchi, Taichung, Taiwan 435, R.O.C., James@mail.ihmt.gov.tw

Follow this and additional works at: https://jmstt.ntou.edu.tw/journal

Part of the Civil and Environmental Engineering Commons

\section{Recommended Citation}

Huang, Wen-Chih and Chu, Chin-Yuan (2004) "A Selection Model for In-Terminal Container Handling Systems," Journal of Marine Science and Technology. Vol. 12: Iss. 3, Article 4.

DOI: $10.51400 / 2709-6998.2234$

Available at: https://jmstt.ntou.edu.tw/journal/vol12/iss3/4

This Research Article is brought to you for free and open access by Journal of Marine Science and Technology. It has been accepted for inclusion in Journal of Marine Science and Technology by an authorized editor of Journal of Marine Science and Technology. 


\title{
A SELECTION MODEL FOR IN-TERMINAL CONTAINER HANDLING SYSTEMS
}

\author{
Wen-Chih Huang* and Chin-Yuan Chu**
}

Key words: cost comparison indicator, container handling system, container yard.

\begin{abstract}
This paper describes the main characteristics of in-terminal container handling systems and analyzes the factors affect the total cost of these handling technologies. A cost model is developed for decision making. It includes land cost, equipment procurement cost, maintenance cost, handling efficiency, labor cost, etc. A handling cost comparison indicator $R_{i / j}$ is also proposed to make the pair comparisons between handling systems and thus to determine the most economical handling technology in the container yard. The results show that for yard cranes to be more economically operation only when procurement cost, yard size, interest rate, number of handlings per container are small and annual throughput is larger. The methodology proposed in this study can be evaluated and implemented for selection of container handling technology, and is anticipated to make considerable contribution to the planning of container terminal design.
\end{abstract}

\section{INTRODUCTION}

The introduction of containerized traffic has changed the seaport terminal greatly; it reduced handling operations at port and at all other transfer point, thus increases the efficiency of handling and speed of transportation, accordingly shorten the cargo movement and ship turnaround time at port. A container terminal provides the location, mechanical devices, space and operating conditions under which the container transfer functions take place. A great variety of handling equipments are involved in container yard operation, such as straddle carriers (SCs), forklifts, rubber-tyred gantries (RTG), rail-mounted gantries (RMG), and tractor-trailers. Terminal handling sys-

Paper Submitted 01/28/04, Accepted 06/08/04. Author for Correspondence: Chin-Yuan Chu.E-mail: James@mail.ihmt.gov.tw.

*Associate Professor, Department of River and Harbor Engineering, National Taiwan Ocean Juniversity, P.O. Box 7-107, Keelung, Taiwan 20224, R.O.C.

**Section Chief, Ministry of Transportation and Communication, Institute of Transportation, Research Center of Harbor and Marine Technology, No. 2, Chung-Hen $10^{\text {th }}$ Rd., Wuchi, Taichung, Taiwan 435, R.O.C. tems can be categorized on the basis of using combinations of these equipments in conjunction with the movement of containers by tractor/trailer between the quayside and the storage yard into tractor-trailer system, straddle carrier system, rubber-tyred gantry crane system, railmounted gantry crane system and combination systems.

Main determinants related to the investment of terminal handling system are: land availability, handling capacity and operation costs. Both handling capacity and operation costs are directly dependent on the equipment being used and land availability. For many terminals where land prices are at a premium, such as Singapore, Hong Kong, Tokyo and Taiwan, stacking capacity is a major factor. Therefore, RTGs and RMGs are largely accepted for new terminal developments owing to their high stacking ability. Other terminals where land is available, $\mathrm{SCs}$ are popular even though the throughput in excess of one million TEU per year, like Maersk/ECT terminal in Rotterdam, Southampton terminal and Ceres terminal. More over, there are new transshipment terminals such as Medecentre/Gioia Tauro transshipment hub in southern Italy and Hutchinson's Freeport Bahamas adopted exclusive SCs [3].

SCs remain popular because of their relatively low purchase cost, smaller yard development cost and their economic and flexible operations, however, SCs are less space efficient, lower operational capacity and less suited to higher automation and were considered greater downtime and higher maintenance. Yard cranes (RTGs, RMGs) are space-efficient, fast in operation and more suited for automation, however, they are generally required higher development cost than SCs because of their heavy body weight and wheel load. RTGs are typically cheaper to install, more expensive to operate and more flexible than RMGs [1].

A few academic researchers have made attentions on the operational aspects of container terminals. Hatzitheodorou formulated a cost model and presented an indicator to compare total cost of stacking over the total cost of wheeled operations on container yard adopts top loader [10]. Ballis et al. [4] and Chung et al. [9] proposed a simulation analysis to compare of using a 
buffer space as a method to reduce the total container loading time and increase the utilization of handling equipment with the practice adopted by the Port of Portland [9]. Hee and Wijbrands devised models to describe the performance of yard stacker by partition the operation of a container handling into preceding operation and current operation, and these two steps are further divided into putting a container into the stack yard and delivering a container from the stack yard [11]. Mounira et al. examined the minimal storage space needed to implement the recommended strategies under a given traffic [18]. Roux took into account the container arrival and departure pattern then developed a simple analytical technique to estimate the minimum storage capacity needed for import containers [20]. Lee proposed a selection procedure for the determination of container handling techniques at Port of Keelung under specific operation situation [17]. Kap and Hong suggested a conceptual cost model to determine the optimization between space and cranes of import containers [15]. Kozan introduced a network model to analyze the investment of multimode container terminal [16]. Zhow et al. developed a simulation program to calculate the total operation cost and revenue of a private operated container terminal on the basis of various handling efficiency and annual throughput [25]. Kao evaluated stacking strategies on container space and formulated an integer-programming model to minimize the unproductive moves [14]. Chu and Huang proposed the annual handling capacity of terminals base on function of handling efficiency, yard sizes, equipments adopted and operation conditions $[6,7,8]$. And in their latter research, Huang and Chu made cost comparisons between SC direct and relay systems, it is revealed that direct system is preferred when annual throughput is small and container handling cost and transportation cost between apron and stacking yard by truck are large [12]. However, the results were not further incorporated with the choosing procedure for both RTG and RMG technologies.

In this paper, only pure straddle carrier system, rubber-tyred gantry crane system and rail-mounted gantry crane system are analyzed. Besides, the dimension (internal span, stack height) and the type (SC, RTG, RMG) of the equipment that evidently influence the handling efficiency and thus the stacking capacity of containers are also considered. However, it would be too complicated to involve all dimensions of each type of equipment into comparisons. Thus, only one most popular dimension of each type of machinery is being analyzed. A two stages decision process for the choosing of container handling system is developed. Firstly, determining the container yard sizes with handling equipments and handling capability that meet the demand of annual throughput. Secondly, makes comparisons of total annual costs of terminals which adopt SC handling system, RTG handling system and RMG handling system, for the purpose of assisting the terminal operator in choosing the least handling cost technique. The trade-off among these three handling system will be analyzed by an assigned handling cost comparative indicator " $R_{i / j}$ ".

\section{IN-TERMINAL CONTAINER HANDLING SYSTEMS}

\section{SC handling system}

SC system relies on a single piece of equipment for operations in the container yard and serving the ships, the system can be divided into SC direct and SC relay systems, base on the ways of transporting containers between apron and yard. In the SC direct system, the SCs directly access the box from the quay crane and move them between quayside and container yard, and load/unload containers to/from truck/tractor. Whereas in the SC relay system, boxes are transferred by yard tractor/trailer units, and the SC picks up the boxes from the roadway and move along the rows to stack them on the yard [21]. SCs are maneuverable, flexible in operation and relatively high speed of movement. SC fleets can be easily deployed to different activities in respond to varying traffic demands. In the past, these machines had a poor reliability record, poor visibility, higher maintenance, higher operation costs and a short economic life, thus only suitable for low container storage and with spacious of land. However, with the modification of the machines (diesel-electric and hydrostatic models are faster and cleaner in operation and more reliable), demand for SC units continuous to be strong, particular in European ports [1, 2, 3].

SCs capable of stacking two, three even four high, Containerisation International indicated that only about $10 \%$ of the SCs capable of 1 -over-3 stacking [1]. The majority of stack height is 1-over- 2 and with very little number up to 1-over-3 stacking in the container terminals of Taiwan [24].

\section{RTG handling system}

The basic RTG design is largely standardized. It is space-efficient, fast in operation, and offers scope for advanced automation. Because they do not follow a fixed rail-track, thus offer a more flexible operation [1, $2,3]$. In this system, containers are stacked by RTGs in the storage area, which move on rubber-tyred wheel to handle the containers up to eight rows plus a truck lane for tractor-trailer units to drive. Tractor-trailer units 
make the movement of containers between the quayside and container yard. Very heavy concrete paving is required in the wheel tracking areas to support the heavy wheel loads, besides, there are concrete/steel pads necessary for the turning purpose of the cranes to travel to adjacent storage area to implement stacking operations. RTGs are generally smaller and lighter than RMGs, therefore, they are likely to be preferable for terminals built on reclaimed marshland, where reinforced piling would be too costly. RTGs can stack containers up to one over seven high, more than $45 \%$ of world units lift one over four; about $80 \%$ of world units capable of straddling six containers width plus lane [1]. Yang et al. summarized that the majority of the units in Taiwan ports stack one over four high and capable of straddle six rows of container plus one truck lane [24].

\section{RMG handling system}

RMGs travel on fixed rail-track with cantilever outside the portal of cranes. There is no interchange area required in a full RMG system. Road vehicles are allowed onto the terminal and along the truck lane to the appropriate row, which located at each side of the RMG, for receipt/delivery purpose. RMG handling system provides high-density storage along with fast operation. The size and structure of the RMG is determined according to the requirements of the terminal operator, usually a wide RMG can stack as high as one over eight and 12 containers wide. They are generally stack higher, span wider, easier to automate, more durable and reliable than RTGs, however, they are more expensive to install, less flexible in operation and more difficult to change layout in the yard [3]. However, the procurement cost and construction cost have been dropping since local producer emerged in this market. About two thirds of all RMG units in the world can only stack of 1over- 3 high, with just $14 \%$ going 1 -over-4, however, the share of 1-over-5 units going greater and greater [1]. Yang et al. expressed that the stack height of RMG units deployed at Taiwan ports are between 1-over-4 and 1over- 6 , and the internal span of the primary units can place 11-13 rows. About 2-3 truck lanes are deployed under the cantilever at each side of the RMG; half of them are usually used for container stacked [24].

\section{COST FUNCTION MODELING}

One of the rather difficult decisions terminal operators must often makes is the handling system adopted in the container yard. There is actually no fix answer to this question. Many factors affect the layout of a terminal and the selection of in-terminal handling technology. Among these are: the land area available for terminal use, the annual throughput of containers to be handled by the terminal, the handling capacity that the equipment provide, the reliability of the equipment, ease of maintenance and repair, strength of construction, anticipated economic life of the piece of equipment, noise caused by the equipment, and etc. These factors can be varied from terminal to terminal, however, in the end, the dominant factor is economics. Within the available area, different systems for handling containers may be adopted by the terminal operator in order to minimize total annual cost. In summary, in the decision making process for the choosing of container handling system can be divided into two stages: the first step is to determine the container yard sizes with handling equipments and handling capability that meet the demand of annual throughput of containers. Then makes cost comparisons between these handling system in order to find a least costly technique.

The operation systems under comparisons are RTG system, RMG system and SC relay system. The major difference between these systems is the stacking equipment adopted in the container yard. Costs involved in the handling systems are: cost of land, cost of terminal development, cost of equipment and cost of labor. If the residual cost of the equipments, possible price rose of the land cost in the future, administration cost and related office operation cost are not considered. The cost of land is equal to the annual rental cost if the terminal operator does not own the land, or the opportunity cost of the land if the terminal operator owns the land and invests the terminal developments. The terminal development cost, including the annual maintenance and amortization cost of the yard is crucial to terminal operator. The total annual cost of equipment is equal to the capital cost, annual depreciation charge, operation and maintenance cost tied up with the equipment. The cost of labor is equal to the annual salaries and benefits for the equipment drivers and dock foremen. The cost of capital equals to the interest paid if the equipment is bought with borrowed capital, or the opportunity cost if the equipment is purchased free of debt. Different handling system requires different handling facility, and because of their different body weights and installation requirement, subsequently greatly affect the total annual cost of the system. As a consequent, there is an economic trade-off among the land cost, yard development cost, equipment purchase cost and operation costs involve in the choice of container handling system. Total annual cost of a "pure" in-terminal handling system can be expressed as:

$$
\begin{aligned}
T C_{j} & =C L \times A_{j} \times r+C Y_{j} \times A_{j} \times\left(r+r y_{j}+m y_{j}\right) \\
& +\frac{\left(Q \times n h_{j}\right)}{H C_{j} \times\left(1-r d_{j}\right)} \times\left(C P_{j} \times\left(r+r c_{j}\right)+C M_{j}\right.
\end{aligned}
$$




$$
\begin{gathered}
\left.+C O_{j}+C W_{j}\right)+T_{j} \times Q+C R_{j} \\
r y_{j}=\frac{r}{1-(1+r)^{-n y_{j}}} ; r c_{j}=\frac{r}{1-(1+r)^{-n c_{j}}}
\end{gathered}
$$

In which $T C_{j}=$ total annual cost for any handling system, in US\$ per year; $C L_{j}=$ unit cost of land, in dollars per square meter per year; $A_{j}=$ area capable of accommodating designed annual throughput, in square meter; $C Y_{j}=$ unit yard development cost, in dollars per square meter; $r=$ interest rate, in percentage; $r y_{j}, r c_{j}=$ annual amortization factor for container yard and handling equipment respectively; $r d_{j}=$ a reserved ratio for equipment breakdowns and preventive maintenance, in percentage $m y_{j}=$ maintenance cost of yard as a percentage of new value; $n y_{j}, n c_{j}=$ economic life of container yard and handling equipment respectively, in years; $C Y_{j}$ $\times A_{j} \times r=$ annual cost of yard development capital; $C Y_{j}$ $\times A_{j} \times r y_{j}=$ annual depreciation cost of container yard development; $C Y_{j} \times A_{j} \times m y_{j}=$ annual container yard maintenance cost; $Q=$ annual throughput of containers, in units/yr; $n h_{j}=$ average number of handlings per container in the yard, includes deliveries/receipts and marshalling operations (rearranging or searching for containers at the lower level of stacking); $H C_{j}=$ average number of containers a crane handled per year, in units/ yr; $C P_{j}=$ procurement cost of a crane, in US $\$ C P_{j} \times r$ $=$ annual cost of crane capital; $C P_{j} \times r c_{j}=$ annual depreciation cost of crane; $C O_{j}=$ operation cost per crane unit $=$ container handling cost per box $\left(c c_{j}\right) \times$ number of containers handled, in US\$ per year; $C M_{j}=$ maintenance cost of a crane per year $=C P_{j} \times r m_{j}$, in US\$ per year, $r m_{j}=$ annual maintenance cost of a crane as a currently new value, in percentage; $Q \times n h_{j} /\left(H C_{j} \times(1-\right.$ $\left.\left.r d_{j}\right)\right)=$ number of cranes equipped; $T_{j}=$ transportation cost by truck/tractor between apron and container yard per unit, in US\$ per container; $T_{j} \times Q=$ total transportation cost between quay side and container yard, in US\$ per year; $C W_{j}=$ cost of personnel required for the operation of the handling equipment, in US\$ per year; $C R_{j}=$ cost of dock foreman for the coordination between quay crane and truck/tractor loading/unloading operations, in US\$ per year. The subscript " $j$ " of each variable in equations (1) and (2) represents the different handling system that the terminal adopted, either $S C$, $R T G$ or $R M G$ system. Compares to the cost function proposed by other researchers in container terminal operation $[10,17]$, the cost function presented in this paper takes more constituent factors for a container handling system into account, such as costs related to terminal development and maintenance, cost related to the transportation between apron and container yard, equipment down time ratio and the number of container handlings in the yard for different handling systems.
Consequently, makes the cost function proposed in this paper more practically as a whole.

For $S C$ operations to be preferred over $R T G$ and $R M G$ handling systems, $T C_{S C}<T C_{R T G}$ and $T C_{S C}<$ $T C_{R M G}$ and for $R T G$ operations to be preferred over $R M G$ system, $T C_{R T G}<T C_{R M G}$. In order to make the pair comparisons among these three systems, a handling cost comparison indicator $R_{i / j}\left(R_{i / j}=T C_{i} / T C_{j}\right)$ is proposed $[10,12]$, for $R_{i / j}>1$ situations, " $j$ " handling system is preferred, on the contrary, " $i$ " handling system is preferred for $R_{i / j}<1$, the description of $R_{i / j}$ is shown as Figure 1.

\section{COST COMPONENTS ANALYSIS}

Many parameters involved in the aforementioned cost functions, some of them are addressed more detailed as follow.

\section{Procurement cost of equipments $(C P)$}

A typical purchase price in mid-1980s was about US\$0.5 million for a $S C$ capable of stacking containers three high, and a $R T G$ crane costs approximately US $\$ 0.75$ million and a $R M G$ crane, including rails, costs about US\$1.5 million [21]. However, the purchase price of the equipment is dependent on the purchase timing, order size of the procurement, the essential specifications of the cranes (sizes, capability, travel speed, degree of automation and so on), negotiation ability of the buyer, manufacturer of the crane, location of client, etc. The combined contracted value of the total figure of 438 SCs (the ability of stack height is not mentioned) delivered in 1995-1997 was about US\$300-400 million, and the cheapest machines cost about US\$0.6 million per unit, although most tenders cover a unit cost of at least US\$0.7-0.8 million [1]. For the terminals at Port of Kaohsiung, the equipment costs about US\$0.5-0.7 million per unit [19], the price is varied between operators. The total cost of 468 RTGs contracted during 1995-1996 was estimated at between US\$550-700 million, range from US\$1.1 million to US\$1.5 million per RTG crane. RTG remains around

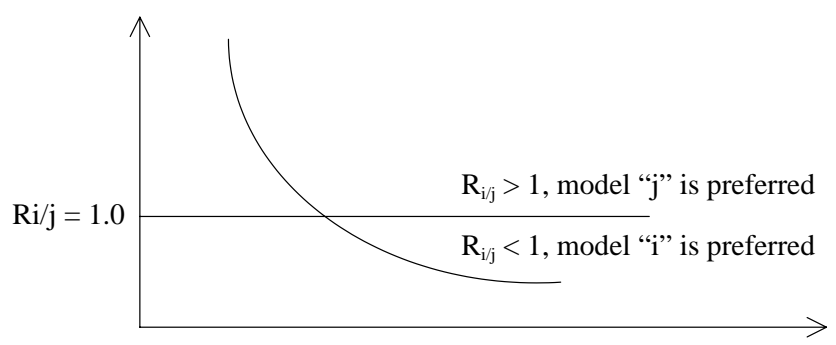

Fig. 1. Using $\boldsymbol{R}_{i j}$ on handling systems selection. 
US\$1 million and above per crane, because the primary component parts of the crane are manufactured outside of Taiwan [19]. RTG cranes typically 2-4 times less than a corresponding unit. It was estimated about US $\$ 800$ million for $172 R M G s$, range around US\$3 million to 5 million per crane [1]. However, procurement cost of $R M G$ has down dramatically since local manufactures are capable of supplying the machines in Taiwan, it costs around US\$0.8-1.5 million per crane, according to the dimension and the degree of automation of the crane $[19,22,24]$.

\section{Economic life of equipments (nc)}

The UNCTAD has recommended a certain length of economic life for port structures and equipment to serve as guidance to the planner. The recommended average economic life of $S C s$ is about six years [21]; Containerisation International concluded that $S C s$ are typically operated for 15-20 years maximum [1]; the Port of Kaohsiung authority suggested 12 years of economic life for both $S C s$ and RTGs. However, no recommendation is made on economic life of RMGs [19]. For the study on the majority terminal operators, 10-year lift-span on $S C s$, 15-year lift-span on RTGs and 20-year lift-span on RMGs are recommended [22, 24]. These are only guidelines and cannot be substitute for one's own experience in the field. The actual life will, however, depend on the extent of utilization, maintenance efficiency and other environmental factors.

\section{Operation cost of equipments $(\mathrm{CO})$}

Annual operation cost per crane is equal to the production of number of containers handled per year and handling cost per box. For a $S C$ relay system, the $S C$ travels to and from access aisle ways between blocks and stacked rows or between exchange area and stacked containers. However, for a $R T G$ and $R M G$ handling systems, trucks are allowed onto the portal to move containers. $S C$ is typically lighter than $R T G$ units. Both $S C$ and $R T G$ units are basically diesel driven. $R M G$ units are generally electricity driven on the fix railtracks. It cost about US\$0.6/move to operate in the $S C$ relay system, and the cost ratio between $R T G / S C / R M G$ is about 1:0.8:0.5 [19].

\section{Container yard development cost $(C Y)$}

Many factors affects the physical features of the terminal site and subsequent investment on civil engineering, such as hydrograph and topography, meteorological and oceanography influences, coastal hydraulics, and subsoil characteristics on land and un- der the sea [21]. Therefore, it is difficult to estimate a precise construction cost of a terminal without any given site conditions. For a selected quay structures and location of terminal, the difference of yard development cost between handling systems not only depend on the weight of crane or load of wheel in order to meet different requirement of infrastructure and surfacing, but also on the auxiliary facilities. For a $S C$ unit, total weight 90-100 $T$ is spread on 8 wheels; for a $R T G$ unit, around $25 \mathrm{~T} /$ wheel are on the four wheels left side, $20 \mathrm{~T} / \mathrm{wheel}$ are on the four wheels right side, and for a $R M G$ unit, about $25 \mathrm{~T} /$ wheel are on 16 wheels on four corners [13]. For an asphalt surfacing, it cost about US\$35-40 per square meter, and about US\$70 per square meter for a concrete surfacing. $R M G$ with its paving and auxiliary facilities cost about US\$90 per square meter $[19,22]$.

\section{Annual maintenance cost of equipments and container yard $(C M, \mathrm{my})$}

The UNCTAD suggested $12 \%$ of capital cost (rm) for SC yearly maintenance during the whole economic life [21]. Port of Kaohsiung authority suggested 4\%-7\% for upper-bound percentage and 1.5\%-2.5\% for lowerbound percentage of annual maintenance on the basis of the $S C$ age; and $3.2 \%-7 \%$ for upper-bound percentage and $1.2 \%-4.5 \%$ for lower-bound annual maintenance cost of RTGs. Yangming Marine Kaohsiung Terminal had undergone an experience of about $6 \%$ annual maintenance cost operating their $S C$ fleet. For the electricity driven $R M G s$, the annual maintenance cost is much lower than diesel operated RTG units [19].

For the annual maintenance costs of container yard (my), the UNCTAD suggested $1.00 \%$ for concrete apron or roads and $1.50 \%$ for asphalt surface [21]. While Institute of Transportation suggested $0.75 \%$ for civil engineering and surfacing, this value is similar with the operation experience of terminal operators in Taiwan [13].

\section{Handling capacity of equipments $(H C)$}

Naturally, cost minimization and operation efficiency should be of concern to terminal operators. When choosing the equipment which the higher the density of the stack together with the wider internal span of the crane, the higher the number of wasted moves for container retrieval (i.e. nh is larger), and thus has some effect on the comparative performance of different types of equipment. Shifting a container requires several small movements of trolley, bridge and hook. Hee and Wijbrands [11] and Chen [5] devised analytical method to describe the performance of yard cranes $(R T G, R M G)$ 
by partition the operation of a container handling into four time sub-models: (1) the current operation is a slave trailer, whereas the preceding operation was an external truck; (2) the current operation is a slave trailer, whereas the preceding operation was a slave trailer; (3) the current operation is an external truck and the preceding operation was an external truck; and (4) the current operation is an external truck and the preceding operation was a slave trailer, and found that factors like the rate between the arrival rate of external trucks and the rate of slave trailers (internal trucks), and the utilization of stack yard have stronger effect on container handling efficiency of a crane than that of the maximum stacked height of containers and the length of the bridge, which directly links to the crane capability. Accordingly, it is very difficult to conclude the true number of boxes handled by each type of equipment with various dimension combinations then makes an obvious productivity difference between $S C, R T G$ and $R M G$ in terms of moves per hour base. The alternative is to adopt a full container simulation model on the basis of various operation strategies and layouts of terminal. However, this paper looks at the comparisons from a macro planning point of view rather than analyze the handling difference between cranes in detail, therefore, the handling data will gather from the practical day to day terminal operation results.

The cycle time $(h c)$ for a $S C, R T G$, and $R M G$ to stack/straddle a box takes around 1.5-3 min, 2.5-3 min, and 2-2.5 min, respectively [19, 22, 24]. Thus the annual handling capacity for a $S C$ working at the yard would be: $(365$ days/yr. $\times 80 \% \times 1,220 \mathrm{~min} /$ day $\times 60 \%) /$ $2 \mathrm{~min} / \mathrm{move}=106,872 \mathrm{moves} / \mathrm{yr}$, about $160,000 \mathrm{TEUs}$ (assume $h c_{S C}=2 \mathrm{~min} / \mathrm{move}$ ). And 71,248 moves $/ \mathrm{yr}$ for a $R T G$ assume $h c_{R T G}=3 \mathrm{~min} / \mathrm{move}, 85,500 \mathrm{moves} / \mathrm{yr}$ for a $R M G$ assume $h c_{R M G}=2.5 \mathrm{~min} / \mathrm{move}$. On the basis of $80 \%$ workday per year, 1,220 work-minute per day and $60 \%$ operation time ratio spent on handling containers [13]. With these figures and the number of container handlings $(n h)$, annual throughput $(Q)$ and equipment handling capacity $(H C)$, one can easily calculate the number of cranes required for different type of handling system.

\section{Transportation cost between quayside and storage $\operatorname{area}(T)$}

For the terminals adopt $S C$ relay system, $R T G$ handling system and $R M G$ operations, external truck companies are contracted to implement the boxes transferred works in Taiwan ports. The truck companies must provide sufficient number of trucks to fulfill the service-level demands of the terminal operator and are responsible for salary, benefits of the truck-drivers and all the operation cost (fuel, maintenance, insurance and etc.) of the trucks. Whereas the terminal operators pay the truck companies depends on the number of containers they move on an agreement price per box base. Currently, the contracted price is about US\$5 per unit [19].

\section{Personnel cost $(C W, C R)$}

Each crane (SC/RTG/RMG) requires three operators (3 shifts/day). Besides, one dock foreman is provided for every working gantry crane in charge of the coordination work between quay crane and truck operation on the quay apron. These payments are the burden of terminal operators themselves other than truck companies. Other personnel requirements for gatehouse operations, yard control office and operations, terminal support operations are assumed the same among systems. It is approximated US $\$ 20,000$ and US $\$ 13,000$ per year for each driver and foreman, respectively [19, $24,25]$.

\section{IN-TERMINAL HANDLING SYSTEM SELECTION}

\section{Annual throughput $(Q)$ and handling capacity of container yards}

Annual throughput of containers in a container terminal is generally shown as the annual total number of containers (usually expressed in TEU) exchanged between ships and quay. An export or import container from or to the hinterland, usually occupies 1 TEU of space in the marshalling yard for 1 TEU of throughput in the terminal. On the other hand, a transshipped container usually occupies 1 TEU of space in the yard for 2 TEU of throughput in the terminal in terms of ship unloading and loading. Therefore, annual handling capacity of a container yard is greatly dependent upon container storage capacity, transshipment rate and annual turnover based on average dwell days of containers through the yard. Container storage capacity is expressed as the production of mean stacking height of containers and number of container ground slots (or area requirement per ground slot). Consequently, with the variety of transshipment ratio and dwell days of containers, there would be various storage capacities that meet the same throughput. The average dwelling time of container status and the annual container handling capacity are computed by [23]:

$$
D=[\mu D t+(1-\mu) D e+(1-\mu) D i] / 2
$$




$$
\begin{aligned}
C & =(365 \times 2 \times C s) /[(\mu \times D t) / H t+(1-\mu) \times D e / H e \\
& +(1-\mu) \times D i / H i]
\end{aligned}
$$

Where $C s$ is the total number of $T G S s$ that a $C Y$ could supply, $\mu$ is the transshipment container ratio, $D t$, $D i, D e$ are average dwell times of transshipped containers, import containers and export containers, respectively; and $\mathrm{Ht}, \mathrm{Hi}, \mathrm{He}$ are stacking height of transshipped containers, import containers and export containers on the basis of accessibility index of stacked containers. The average dwell times are range 3-7 days for import containers; and 3-5 days and 3-7 days for export and transship containers at the major container terminals of Kaohsiung [19].

Chu and Huang have made a comprehensive study on the handling capacities under various container yard sizes, transshipment ratio, average dwelling days of containers and various handling cranes. For a container yard with $320 \mathrm{~m}$ quay length and $300 \mathrm{~m}$ and $400 \mathrm{~m}$ yard depth, transshipment ratio ranges $40 \%$ $60 \%$, average dwelling days of container between 3-7 days, equipped cranes like SCs (1 over 2), RTGs (1 over 4 , span 6 boxes plus track lane), RMGs ( 1 over 6 , spans of $11+2+2$ lanes), the handling capacity of the terminals are shown as Table 1. Assume the planned annual throughput for a one-berth terminal is around
450,000 TEU (about 30,000 units). Then a $320 \mathrm{~m} \times$ $400 \mathrm{~m}$ container yard with either SC operations, or $R T G$ handling system or RMG handling system should be sufficient to meet the demand. Besides, for terminals adopt $R T G / R M G$ system, a smaller size of yard $(320 \mathrm{~m}$ $\times 300 \mathrm{~m}$ ) with less than 4.25 days dwell time also capable of handling the throughput $[6,7,8]$.

\section{Cost computation on each handling system}

Assume the given values of all the constituent parameters in the cost function are shown as Table 2, container yard $A=12.8$ ha, interest rate $r=6 \%$, land cost $C L=\mathrm{US} \$ 100 / \mathrm{m}^{2}$, designed annual throughput $Q=$ 300,000 units/yr (about 450,000 TEU/yr), yard development cost $C Y=35 / 70 / 90 \mathrm{US} \$ / \mathrm{m}^{2}$, cycle time $h c=2 /$ $3 / 2.5 \mathrm{~min} / \mathrm{move}$, procurement cost of crane $C P=0.8 / 1 /$ 1.5 million US\$/unit, maintenance cost ratio of crane $\mathrm{rm}$ $=6 \% / 8 \% / 3 \%$, handling cost $c c=0.6 / 0.8 / 0.4 \mathrm{US} \$ /$ move, and average number of handlings per box at yard $n h=$ $2.2,2.5,3$ moves/unit for $S C / R T G / R M G$, then the annual total cost per container would be US $\$ 18 / 26 / 27$ (base on equation (1) and annual throughput) for $S C /$ $R T G / R M G$. SC handling system reveals the least cost under previous given condition. If container yard changed from 12.8 ha to 9.6 ha for $R T G$ and $R M G$ systems, and other factors remain the same, then the

\begin{tabular}{|c|c|c|c|c|c|c|c|}
\hline \multirow{3}{*}{$\begin{array}{c}\text { Transship } \\
\text { Ratio } \\
(\%)\end{array}$} & \multirow{3}{*}{$\begin{array}{c}\text { Average } \\
\text { Dwell } \\
\text { Time (days) }\end{array}$} & \multicolumn{2}{|c|}{$\mathrm{SC}$} & \multicolumn{2}{|c|}{ RTG } & \multicolumn{2}{|c|}{ RMG } \\
\hline & & \multicolumn{2}{|c|}{1 over 2} & \multicolumn{2}{|c|}{1 over $4,6+1$} & \multicolumn{2}{|c|}{1 over $6,11+2+2$} \\
\hline & & $320 \times 400 \mathrm{~m}^{2}$ & $320 \times 300 \mathrm{~m}^{2}$ & $320 \times 400 \mathrm{~m}^{2}$ & $320 \times 300 \mathrm{~m}^{2}$ & $320 \times 400 \mathrm{~m}^{2}$ & $320 \times 300 \mathrm{~m}^{2}$ \\
\hline \multirow{6}{*}{40} & 3.6 & 617,845 & 464,545 & 764,074 & 560,321 & $1,073,844$ & 767,031 \\
\hline & 4.4 & 517,484 & 389,086 & 635,388 & 465,951 & 889,592 & 635,422 \\
\hline & 5.7 & 377,572 & 283,888 & 471,577 & 345,823 & 666,300 & 475,929 \\
\hline & 6.5 & 337,564 & 253,807 & 419,179 & 307,398 & 590,423 & 421,730 \\
\hline & 6.9 & 320,580 & 241,037 & 397,117 & 291,219 & 558,615 & 399,011 \\
\hline & 7.7 & 291,270 & 219,000 & 359,296 & 263,484 & 504,282 & 360,201 \\
\hline \multirow{6}{*}{50} & 3.25 & 691,149 & 519,661 & 852,167 & 624,922 & $1,195,740$ & 854,100 \\
\hline & 4.25 & 543,704 & 408,800 & 664,534 & 487,325 & 928,161 & 662,972 \\
\hline & 5 & 433,806 & 326,170 & 540,554 & 396,406 & 762,799 & 544,856 \\
\hline & 6 & 370,707 & 278,727 & 458,444 & 336,192 & 644,306 & 460,218 \\
\hline & 6 & 370,707 & 278,727 & 458,444 & 336,192 & 644,306 & 460,218 \\
\hline & 7 & 323,633 & 243,333 & 397,990 & 291,859 & 557,677 & 398,340 \\
\hline \multirow{6}{*}{60} & 2.9 & 784,188 & 589,615 & 963,221 & 706,362 & $1,348,853$ & 963,466 \\
\hline & 4.1 & 572,721 & 430,617 & 696,483 & 510,754 & 970,227 & 693,019 \\
\hline & 4.3 & 509,722 & 383,250 & 633,166 & 464,322 & 891,983 & 637,131 \\
\hline & 5.1 & 439,415 & 330,387 & 542,172 & 397,593 & 761,050 & 543,607 \\
\hline & 5.5 & 411,066 & 309,072 & 505,825 & 370,938 & 709,012 & 506,437 \\
\hline & 6.3 & 364,087 & 273,750 & 446,023 & 327,084 & 623,717 & 445,512 \\
\hline
\end{tabular}

Table 1. Annual container handling capacity (TEUs/yr)

Source: [6, 7] 
Table 2. Parameters of comparisons

\begin{tabular}{|c|c|c|c|}
\hline Parameters & $\begin{array}{c}\text { SC } \\
(1 \text { over } 2)\end{array}$ & $\begin{array}{c}\text { RTG } \\
(1 \text { over } 4,6+1)\end{array}$ & $\begin{array}{c}\text { RMG } \\
(1 \text { over } 6,11+2+2)\end{array}$ \\
\hline Equipment cost $(\mathrm{CP})$ & US\$0.8 million & US\$1 million & US $\$ 1.5$ million \\
\hline Economic life of equipment (nc) & $10 \mathrm{yrs}$ & $15 \mathrm{yrs}$ & $20 \mathrm{yrs}$ \\
\hline Economic life of yard (ny) & 40 & 40 & 40 \\
\hline Handling cost per box (cc) & US\$0.6 & US $\$ 0.8$ & US\$0.4 \\
\hline Equipment maintenance cost (rm) & $6 \%$ & $8 \%$ & $3 \%$ \\
\hline Cycle time (hc) & $2 \mathrm{~min} /$ move & $3 \mathrm{~min} /$ move & $2.5 \mathrm{~min} / \mathrm{move}$ \\
\hline Transportation cost $(\mathrm{T})$ & US\$5/unit & US\$5/unit & US\$5/unit \\
\hline Yard development (CY) & $\mathrm{US} \$ 35 / \mathrm{m}^{2}$ & $\mathrm{US} \$ 70 / \mathrm{m}^{2}$ & $\mathrm{US} \$ 90 / \mathrm{m}^{2}$ \\
\hline Annual driver cost & US $\$ 20,000 /$ man & US $\$ 20,000 /$ man & US $\$ 20,000 / \mathrm{man}$ \\
\hline Annual dock foreman cost & US\$13,000/man & US $\$ 13,000 / \mathrm{man}$ & US $\$ 13,000 /$ man \\
\hline Annual throughput (Q) & 300,000 units & 300,000 units & 300,000 units \\
\hline Number of handlings at yard (nh) & 2.2 moves/unit & 2.5 moves/unit & 3 moves/unit \\
\hline Equipment reserved ratio (rd) & $20 \%$ & $10 \%$ & $5 \%$ \\
\hline Land cost $(\mathrm{CL})$ & $\mathrm{US} \$ 100 / \mathrm{m}^{2}$ & $\mathrm{US} \$ 100 / \mathrm{m}^{2}$ & $\mathrm{US} \$ 100 / \mathrm{m}^{2}$ \\
\hline Interest rate $(r)$ & $6 \%$ & $6 \%$ & $6 \%$ \\
\hline Yard maintenance cost (my) & $0.6 \%$ & $0.75 \%$ & $0.5 \%$ \\
\hline
\end{tabular}

Table 3. Sensitivity intensity analyses on annual total cost per box

\begin{tabular}{lccc}
\hline Parameter & SC & RTG & RMG \\
\hline Yard size (A) & 0.248 & 0.252 & 0.279 \\
Cost of land (CL) & 0.140 & 0.098 & 0.094 \\
Yard development cost (CY) & 0.108 & 0.153 & 0.185 \\
Interest rate ( $\mathrm{r}$ ) & 0.351 & 0.389 & 0.491 \\
Yard maintenance cost (my) & 0.005 & 0.009 & 0.007 \\
Cycle time of crane (hc) & 0.386 & 0.465 & 0.439 \\
Annual throughput (Q) & -0.005 & -0.067 & -0.103 \\
Number of handlings at yard (nh) & 0.458 & 0.542 & 0.483 \\
Handling cost per box (cc) & 0.072 & 0.077 & 0.044 \\
Procurement cost of crane (CP) & 0.298 & 0.373 & 0.390 \\
Equipment maintenance cost (rm) & 0.051 & 0.123 & 0.066 \\
Transportation cost (T) & 0.273 & 0.192 & 0.184 \\
\hline
\end{tabular}

annual total cost per container would be US\$24 and US\$25 for RTG and RMG respectively. However, each variable has certain degree of influence on the total cost for each system. Therefore, let sensitivity intensity for individual variable " $A$ " on the total $\operatorname{cost}=\left[\left(\operatorname{cost}_{2}-\right.\right.$ cost 1$) /$ cost $\left._{1}\right] /\left[\left(\right.\right.$ variable $A_{2}-$ variable $\left.A_{1}\right) /$ variable $\left.A_{1}\right]$. The subscript " 1 " represents the original value, while subscript " 2 " represents the value after changed. Each variable shows different degree of influence on different handling system. Variables like number of handlings per container at yard, cycle time of crane, interest rate, procurement cost of crane and yard size all indicate stronger influence on the annual cost per box; which sensitivity intensity values are larger. Other variables like maintenance cost ratio of crane and handling cost per box only reveal slight influence on the result; which sensitivity intensity values are smaller, as shown in Table 3.

\section{In-terminal handling system choosing}

Total annual cost $T C_{S C} / T C_{R T G} / T C_{R M G}$ for $S C / R T G /$ $R M G$ handling system are computed according to equation (1). The handling cost comparison indicator $R_{S C / R T G}=T C_{S C} / T C_{R T G}$ and $R_{S C / R M G}=T C_{S C / T C R M G}$ are also calculated. Obviously, if $R_{S C / R T G}<1$, then $S C$ handling system is preferred. While $R_{S C / R T G}>1$, then $R T G$ system would be more economical operated. Same comparisons may be applied on $R M G$ and $S C$ handling systems. If $R_{S C / R M G}<1$, then $S C$ handling system is preferred. While $R_{S C / R M G}>1$, then $R M G$ system would be more economical. In the comparison between $R T G$ and $R M G$ system, while $R_{S C / R M G}>R_{S C / R T G}$, then $R M G$ is preferred. Since each variable is not fix, a sensitivity analysis on mode of operation is necessary. Let sensitivity intensity for individual variable " $A$ " on the handling cost comparison indicator $R_{i / j}=\left[\left(R_{(i / j) 2}-\right.\right.$ $\left.\left.R_{(i / j) 1}\right) / R_{(i / j) 1}\right] /\left[\left(\right.\right.$ variable $A_{2}$ - variable $\left.A_{1}\right) /$ variable $\left.A_{1}\right]$. The subscript " 1 " represents the original value, while subscript "2" represents the value after changed. The results of sensitivity intensity analysis are shown in Table 4, the table indicates that factors like number of handlings per container at yard $(n h)$, cycle time of crane $(h c)$, yard size $(A)$ and procurement cost of crane $(C P)$ 
Table 4. Sensitivity intensity analyses on $R$-value (system choice)

\begin{tabular}{lccc}
\hline Parameter & $\mathrm{R}_{\text {SC/RTG }}$ & $\mathrm{R}_{\text {SC/RMG }}$ & $\mathrm{R}_{\text {RMG/RTG }}$ \\
\hline Yard size (A) & 0.248 & 0.248 & 0.279 \\
Yard development cost (CY) & 0.108 & 0.108 & 0.293 \\
Maintenance cost of yard (my) & 0.005 & 0.005 & 0.114 \\
Cycle time of crane (hc) & 0.386 & 0.386 & 0.644 \\
Number of handlings at yard (nh) & 0.458 & 0.458 & 0.688 \\
Handling cost per box (cc) & 0.072 & 0.072 & 0.151 \\
Procurement cost of crane (CP) & 0.298 & 0.298 & 0.605 \\
Equipment maintenance cost (rm) & 0.070 & 0.070 & 0.173 \\
\hline
\end{tabular}

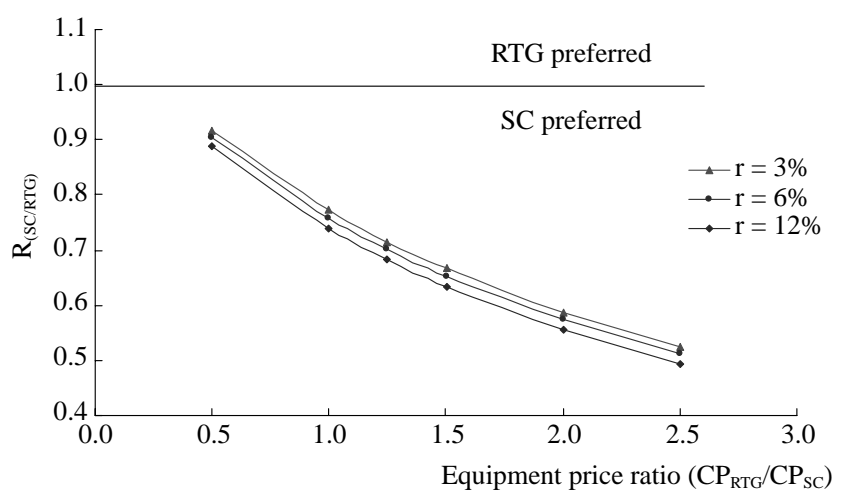

Fig. 2. Handling cost comparison between $S C$ and $R T G$ handling system as a function of $C P$ and $r .\left(C P_{S C}=\mathrm{US} \$ \mathbf{8 0 0 , 0 0 0}\right)$

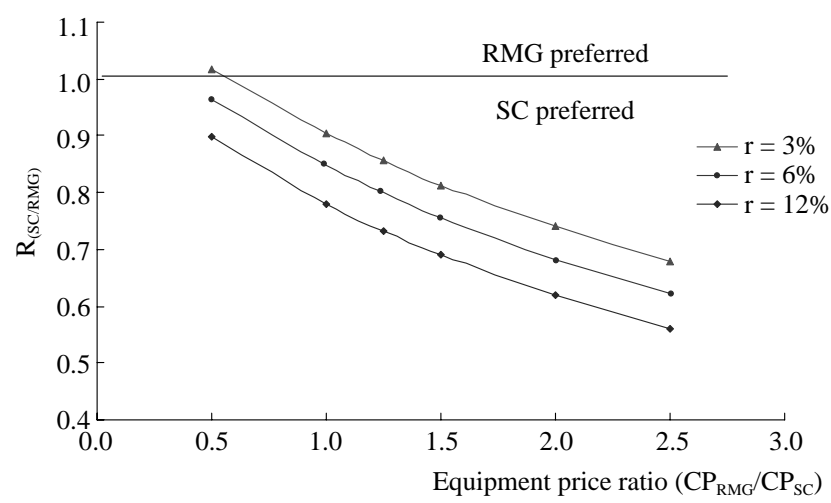

Fig. 3. Handling cost comparison between $S C$ and $R M G$ handling system as a function of $C P$ and $r .\left(C P_{S C}=\mathrm{US} \$ 800,000\right)$

reveals stronger influence on technology choosing. While maintenance cost of yard (my), handling cost per box $(c c)$, maintenance cost of crane $(\mathrm{rm})$ shown very mild influence. Besides these parameters indicate same degree of effect between $S C$ and $R T G$, and $S C$ and $R M G$ selections.

The results of the cost comparison for $S C / R T G$, $S C / R M G$ and $R T G / R M G$ operations are presented in

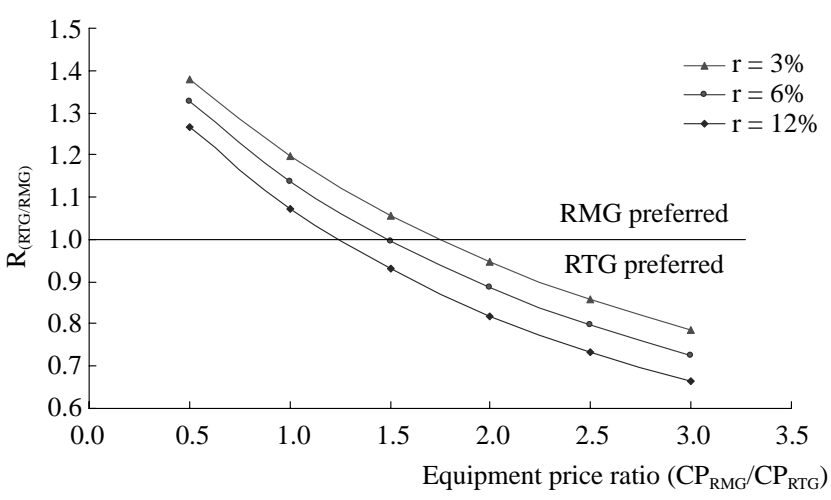

Fig. 4. Handling cost comparison between $R T G$ and $R M G$ handling system as a function of $C P$ and $r$.

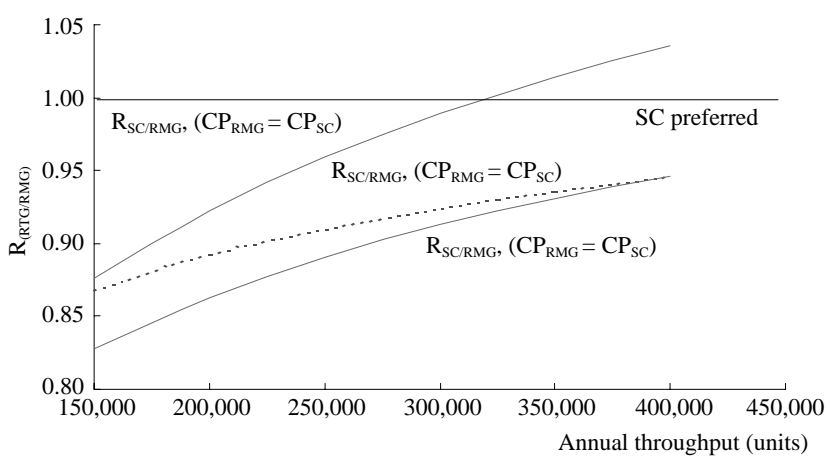

Fig. 5. Handling cost comparison between $S C, R T G$ and $R M G$ handling system as a function of $C P$ and $Q .\left(h c_{S C}=h c_{R T G}=h c_{R M G}\right.$ $=2 \mathrm{~min} / \mathrm{move}, n h_{S C}=n h_{R T G}=n h_{R M G}=2.2 \mathrm{move} / \mathrm{unit}, C P_{S C}=$ $\left.\mathrm{US} \$ 800,000, A_{S C}=A_{R T G}=A_{R M G}=12.8 \mathrm{ha}\right)$

Figures 2-8, interpolations can be made for values of all alternative variables not presented in the figures. Figures 2-4 tend to describe the effect of interest rate and equipment procurement cost on cost comparisons under the given scenarios as shown in Table 2 . It is obvious that an $S C$ operation tends to be preferred (Figures 2-3), although smaller interest rate with lower 


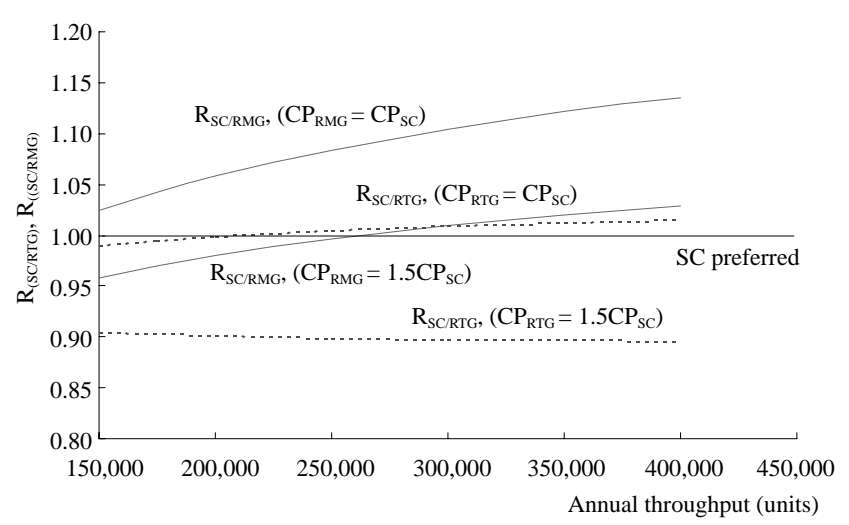

Fig. 6. Handling cost comparison between $S C, R T G$ and $R M G$ handling system as a function of $C P$ and $Q$. $\left(h c_{S C}=h c_{R T G}=h c_{R M G}\right.$ $=2 \mathrm{~min} / \mathrm{move}, n h_{S C}=n h_{R T G}=n h_{R M G}=2.2 \mathrm{move} / \mathrm{unit}, C P_{S C}=$ US\$800,000, $\left.A_{S C}=12.8 \mathrm{ha}, A_{R T G}=A_{R M G}=9.6 \mathrm{ha}\right)$

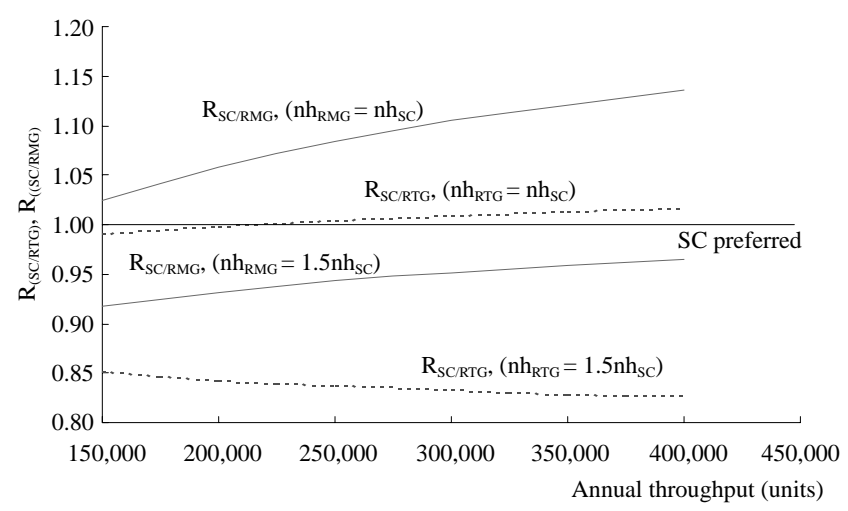

Fig. 7. Handling cost comparison between $S C, R T G$ and $R M G$ handling system as a function of $n h$ and $Q$. $\left(h c_{S C}=h c_{R T G}=h c_{R M G}\right.$ $=2 \mathrm{~min} / \mathrm{move}, \boldsymbol{n h} h_{S C}=2.2 \mathrm{move} / \mathrm{unit}, \boldsymbol{C P _ { S C }}=C P_{R T G}=C P_{R M G}=$ US\$800,000, $A_{S C}=12.8 \mathrm{ha}, A_{R T G}=A_{R M G}=9.6 \mathrm{ha}$ )

procurement cost of $R T G$ and $R M G$ indicate larger $R_{S C / R T G}$ and $R_{S C / R M G}$. Figure 4 shows that lower interest rate reflects advantage for $R M G$ system under the same procurement cost between $R M G$ and $R T G$. However, for $R M G$ system to be preferred than $R T G$ system the procurement cost ratio between $R M G$ and $R T G$ should less than $1.7(r=3 \%)$, otherwise $R T G$ system is favored.

Figure 5 indicate the comparisons base on the annual throughput and equipment cost. Solid lines indicate $R_{S C / R M G}$ scenarios, while dot line indicates $R_{S C / R T G}$ scenario. As the graph shows, $R T G$ always be the modes of less attractive operation, if $h c, n h, C P$ and $A$ between $S C$ and $R T G$ are equal. For $R M G$ operation, if $Q>320,000$ units, $R M G$ becomes more attractive under the same situations. However, as the cost of $R M G$ increases, $C P_{R M G}=1.5 C P_{S C}, R M G$ become less attractive as well. Figure 6 further analyzes the influence of

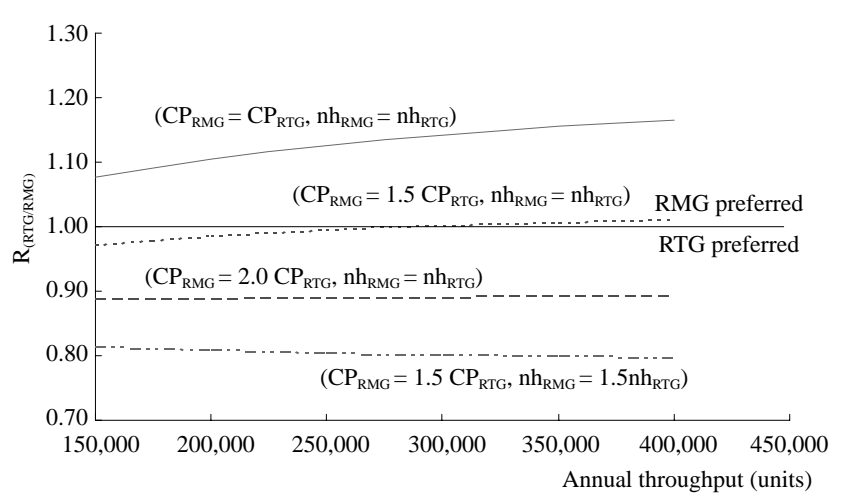

Fig. 8. Handling cost comparison between $R T G$ and $R M G$ handling system as a function of $C P, n h$ and $Q .\left(h c_{R T G}=h c_{R M G}=2 \mathrm{~min} /\right.$ move, $n h_{R T G}=2.5$ move/unit, $C P_{R T G}=\mathrm{US} \$ 1,000,000, A_{R T G}=$ $A_{R M G}=9.6$ ha)

yard size and equipment cost on model selection. If yard size changed from 12.8 ha to 9.6 ha for $R T G$ and $R M G, S C$ remains the same, then $R M G$ always be more preferred if $C P_{R M G}=C P_{S C}$, and $R T G$ always be less preferred if $C P_{R T G}=1.5 C P_{S C}$. For $C P_{R M G}=1.5 C P_{S C}$ and $C P_{R T G}=C P_{S C}$ scenarios, the preference of $R M G$ and $R T G$ is increased as annual throughput increases. As figure 7 shown, if $C P_{R T G}=C P_{R M G}=C P_{S C}$, and $A_{S C}$ $=12.8 \mathrm{ha}, A_{R T G}=A_{R M G}=9.6 \mathrm{ha}, R M G$ always be more attractive than $S C$, for $n h_{R M G}=n h_{S C}$. As number of handlings per box $(n h)$ of $R M G$ increases, the preference of $R M G$ is decreased and $S C$ is preferred, for $n h_{R M G}$ $=1.5 n h_{S C}$. While $n h_{R T G}=n h_{S C}$ and annual throughput larger than 220,000 units, $R T G$ is preferred, however, $R T G$ always be less preferred than $S C$, for $n h_{R T G}=1.5$ $n h_{S C}$. Figures 5-7 conclude that small values of $C P, h c$, and $Q$ for $R T G / R M G$ handling system indicate small values of “ $R$ ", i.e. less preferred for $S C$ handling.

In Figure 8, while $C P_{R M G}=C P_{R T G}=\mathrm{US} \$ 1$ million, $h c_{R M G}=h c_{R T G}=2 \mathrm{~min} / \mathrm{move}$, and $n h_{R M G}=n h_{R T G}=2.5$ move/unit, $R M G$ handling system is preferred. While procurement cost of $R M G$ increases to $C P_{R M G}=1.5$ $C P_{R T G}$, other parameters remain the same, then annual throughput should larger than 280,000 moves for $R M G$ to be preferred. If procurement cost of $R M G$ continually increases to $C P_{R M G}=2.0 C P_{R T G}$, then $R T G$ handling system becomes preferred. Also while $C P_{R M G}=1.5$ $C P_{R T G}$ and $n h_{R M G}=1.5 n h_{R T G}, R T G$ always be preferred.

\section{CONCLUSION}

In this paper, a two steps decision procedure incorporate with three types of in-terminal container handling system is presented. Firstly, the yard space in conjunction with appropriate type of handling equip- 
ment should be ample to accommodate the designed annual throughput. Secondly, a handling cost comparison indicator $R_{i / j}$ is proposed for pair comparisons, so as to determine a least costly handling technique. The cost function consists factors like land cost, yard development cost, procurement cost of cranes, capital cost, depreciation cost, handling cost, maintenance cost and personnel cost, it also takes into account the annual throughput of the yard and handling efficiency of the cranes.

It is shown that cycle time of crane, number of handlings per container at yard, procurement cost of cranes and yard size play important role on the total annual cost for each handling system, while handling cost per move, maintenance cost of crane and yard, cost of land and yard development, annual throughput reveal small sensitivity on total cost per box. Besides, cycle time of crane, number of handlings per container at yard, yard size, and procurement cost of cranes indicate stronger sensitivity on choosing operation system.

$R T G$ and $R M G$ systems tend to be more preferred than SC system, when procurement cost of yard cranes decrease, yard space is smaller, annual throughput increases and with less number of handlings per box at yard. For procurement cost of $R M G$ up to 1.5 times of $R T G$ procurement cost, $R M G$ system still more preferred than $R T G$ system. The findings in this paper also explain the situations why operators in Taiwan ports are keen to shift their $R T G$ system to $R M G$ system, because procurement cost of $R M G s$ has been dropping dramatically while the price of $R T G s$ remain about the same level. On the other hand, SC handling system is still welcomed by some operators.

Although handling efficiency for various equipments has certain effects on mode of operation selection, however, because the dimensions of cranes varied largely and many factors involved in the determination of handling efficiency, this paper from macro planning aspect and through sensitivity analysis to analyze the influence of the factor, the results of this paper is expected to have contributions in terminal planning.

\section{REFERENCES}

1. Anonym, "Market Analysis: In-Terminal Handling Equipment," Containerisation Int., April (1996).

2. Atkins, W.H., "Modern Marine Terminal Operations and Management," Port of Oakland, USA (1983).

3. Avery, P., "The Future of Container Handling Technology, Cargo Systems," IIR Publications Ltd, UK (1999).

4. Ballis, A., Golias, J., and Abakoumkin, C., "A Comparison Between Conventional and Advanced Handling Systems for Low Volume Container Maritime Terminals," Maritime Policy Manag., Vol. 24, No. 1, pp.
73-92 (1999).

5. Chen, Z.S., "Handling Efficiency Comparisons between Container Operation Equipments," Master Thesis, Institute of Traffic Management, National Cheng Kung University, Tainan, Taiwan (1995).

6. Chu, C.Y. and Huang, W.C., "A Study on Ground Slot Layout and Capacity of Container Yards," Maritime Quart., Vol. 11, No. 4, pp. 15-34 (2002).

7. Chu, C.Y. and Huang, W.C., "Land Planning of Container Yards with Different Handling System," Maritime Res. J., Vol. 13, pp. 47-60 (2002).

8. Chu, C.Y. and Huang, W.C., "Container Handling Capacity Study on Container Yards," Maritime Res. J., Vol. 14, pp. 29-44 (2003).

9. Chung, Y.G., Randhawa, S.U., and Mcdowell, E.D., "A Simulation Analysis for a Transtainer-Based Container Handling Facility," Comput. Ind. Engin., Vol. 14, No. 2, pp. 113-125 (1988).

10. Hatzitheodorou, G.C., "Cost Comparison of Container Handling Techniques," J. Waterway, Port, Coastal Ocean Engin., Vol. 109, No. 1, pp. 54-62 (1983).

11. Hee, K.M. and Wijbrands, R.J., "Decision Support System for Container Terminal Planning," J. Operat. Res., Vol. 34, pp. 262-272 (1988).

12. Huang, W.C. and Chu, C.Y., "Cost Comparison of Straddle Carrier Direct and Relay Systems in Container Terminals," J. Marine Sci. Technol., Vol. 11, No. 4, pp. 197-204 (2003).

13. Institute of Transportation, Ministry of Transportation and Communication, An Introduction to the Terminal Layouts and Design Procedure of Container Terminal, Taiwan (2000).

14. Kao, C.K., "Container Box Stacking Strategies Simulation and Slot Assignment Modeling in Container Yards," Ph.D. Dissertation, Institute of Traffic and Transportation, National Chiao Tung University, Hsichu, Taiwan (2002).

15. Kap, H.K. and Hong, B.K., "The Optimal Determination of the Space Requirement and the Number of Transfer Cranes for Import Containers," Computers Ind. Engin., Vol. 35, No. 3-4, pp. 427-430 (1998).

16. Kozan, E., "Optimising Container Transfers at Multimodal Terminals," Math. Computer Model., Vol. 31, pp. 235-243 (2000).

17. Lee, K.L., "A Model for the Choice of Container Terminal Operations System," J. China College Marine Technol. Commerce, pp. 173-191 (1996).

18. Mounira, T.I., Castilho, B.D., and Daganzo, C. F., "Storage Space vs. Handling Work in Container Terminals," Transport. Res.-B, Vol. 27B, No. 1, pp. 13-32 (1993).

19. Port of Kaohsiung, Handling Capacity Comparison of Container Operation Systems, Kaohsiung, Taiwan (2000).

20. Roux, E.D., "Storage Capacity for Import Containers at 
Seaports," Ph.D. Dissertation, Department of Civil Engineering, University of California, Berkeley, USA (1996).

21. United Nations Conference on Trade and Development, "Port Development-A Handbook for Planners in Developing Countries, TD/B/C.4/175/rev. 1," United Nations, New York (1985).

22. Wang, C.J., "Case Study of Port Project-Concessions of Taipei Port Container Terminal," Proceeding of the 24th Ocean Engineering Conference: Taiwan, pp. 259-
283 (2002).

23. Watanabe, I., "Container Terminal Planning-A Theoretical Approach," World Cargo Publishing, UK (2001).

24. Yang, I.C., Chang, K.M., and Su, J.R., "The Effect of Operation Systems on Efficiency and Capacity of Container Yard," Proceeding of the 23th Ocean Engineering Conference, Taiwan, pp. 569-576 (2001).

25. Zhow, H.P., Chan, K.C., and Wu, C.C., "Operation Cost and Benefit Comparison of Private Container Terminal Operator," Maritime Res. J., Vol. 11, pp. 65-95 (2001). 